\title{
Obtaining of Bismuth Citrates by Precipitation from Nitric Acid Solutions
}

\author{
Ekaterina S. Naydenko* and Yury M. Yukhin \\ Institute of Solid State Chemistry and Mechanochemistry SB RAS \\ 18 Kutateladze Str., Novosibirsk, 630128, Russia
}

Received 27.10.2017, received in revised form 19.11.2017, accepted 03.12.2017

The precipitation of bismuth citrates from nitric acid solutions by the addition of citric acid or trisodium citrate solution, as well as the interaction of solid bismuth oxohydroxonitrates $\left[\mathrm{Bi}_{6} \mathrm{O}_{4}(\mathrm{OH})_{4}\right]\left(\mathrm{NO}_{3}\right)_{6} \cdot 4 \mathrm{H}_{2} \mathrm{O}$, $\left[\mathrm{Bi}_{6} \mathrm{O}_{5}\left(\mathrm{OH}_{3}\right)\right]\left(\mathrm{NO}_{3}\right)_{5} \cdot 3 \mathrm{H}_{2} \mathrm{O}$ and $\left[\mathrm{Bi}_{6} \mathrm{O}_{4}(\mathrm{OH})_{4}\right]\left(\mathrm{NO}_{3}\right)_{6} \cdot \mathrm{H}_{2} \mathrm{O}$ with aqueous solutions of citric acid was investigated using the methods X-ray phase analysis, electron microscopy and chemical analysis. The conditions for the formation of compounds compositions of $\mathrm{BiC}_{6} \mathrm{H}_{5} \mathrm{O}_{7}, \mathrm{BiOC}_{6} \mathrm{H}_{7} \mathrm{O}_{7} \cdot \mathrm{H}_{2} \mathrm{O}$ and $\mathrm{Bi}_{6}(\mathrm{OH})_{6}\left(\mathrm{C}_{6} \mathrm{H}_{5} \mathrm{O}_{7}\right)_{4} \cdot 6 \mathrm{H}_{2} \mathrm{O}$ were determined.

It has been found that high purity bismuth citrate composition of $\mathrm{BiC}_{6} \mathrm{H}_{5} \mathrm{O}_{7}$ is expediently obtained from bismuth nitrate solutions by bismuth precipitating in the form of bismuth oxohydroxonitrate of the compositions $\left[\mathrm{Bi}_{6} \mathrm{O}_{4}(\mathrm{OH})_{3}\right]\left(\mathrm{NO}_{3}\right)_{5} \cdot 3 \mathrm{H}_{2} \mathrm{O}$ or $\left[\mathrm{Bi}_{6} \mathrm{O}_{4}(\mathrm{OH})_{4}\right]\left(\mathrm{NO}_{3}\right)_{6} \cdot \mathrm{H}_{2} \mathrm{O}$ and its converting to bismuth citrate by treatment with citric acid aqueous solution.

Keywords: bismuth citrate, bismuth oxohydroxonitrate, precipitation, nitric acid solutions.

DOI: $10.17516 / 1998-2836-0053$.

(C) Siberian Federal University. All rights reserved

* Corresponding author E-mail address: naydenko@solid.nsc.ru 


\title{
Получение цитратов висмута осаждением \\ из азотнокислых растворов
}

\author{
Е.С. Найденко, Ю.М. Юхин \\ Институт химии твердого тела и механохимии СО РАН \\ Россия, 630128, Новосибирск, ул. Кутателадзе, 18
}

\begin{abstract}
Методами рентгенофазового анализа, электронной микроскопии и химического анализа исследовано осаждение циттратов висмута из азотнокисльх растворов при добавлении $\kappa$ ним растворов лимонной кислоты или трехзамещзенного цчитрата натрия, а также взаимодействие твердых оксогидроксонитратов висмута составов $\left[\mathrm{Bi}_{6} \mathrm{O}_{4}\left(\mathrm{OH}_{4}\right]\left(\mathrm{NO}_{3}\right)_{6} \cdot 4 \mathrm{H}_{2} \mathrm{O}\right.$, $\left[\mathrm{Bi}_{6} \mathrm{O}_{5}\left(\mathrm{OH}_{3}\right)\right]\left(\mathrm{NO}_{3}\right)_{5} \cdot 3 \mathrm{H}_{2} \mathrm{O} \quad$ и $\quad\left[\mathrm{Bi}_{6} \mathrm{O}_{4}(\mathrm{OH})_{4}\right]\left(\mathrm{NO}_{3}\right)_{6} \cdot \mathrm{H}_{2} \mathrm{O} \quad$ c водньлми растворами лимонной кислоты. Определены условия образования соединений состава $\mathrm{BiC}_{6} \mathrm{H}_{5} \mathrm{O}_{7}, \mathrm{BiOC}_{6} \mathrm{H}_{7} \mathrm{O}_{7} \cdot \mathrm{H}_{2} \mathrm{O} u$ $\mathrm{Bi}_{6}(\mathrm{OH})_{6}\left(\mathrm{C}_{6} \mathrm{H}_{5} \mathrm{O}_{7}\right)_{4} \cdot 6 \mathrm{H}_{2} \mathrm{O}$ при осаждении висмута из азотнокисльх растворов.

Установлено, что циитрат висмута состава $\mathrm{BiC}_{6} \mathrm{H}_{5} \mathrm{O}_{7}$ высокой чистоты из висмутсодержащчих азотнокисльх растворов целесообразно получать путем осаждения висмута в виде оксогидроксонитратов состава $\quad\left[\mathrm{Bi}_{6} \mathrm{O}_{4}(\mathrm{OH})_{3}\right]\left(\mathrm{NO}_{3}\right)_{5} \cdot 3 \mathrm{H}_{2} \mathrm{O} \quad$ или $\quad\left[\mathrm{Bi}_{6} \mathrm{O}_{4}(\mathrm{OH})_{4}\right]\left(\mathrm{NO}_{3}\right)_{6} \cdot \mathrm{H}_{2} \mathrm{O} \quad u$ дальнейтего перевода их в ичитрат висмута обработкой водным раствором лимонной кислоты.
\end{abstract}

Ключевые слова: ичитрат висмута, оксогидроксонитрат висмута, осаждение, азотнокислье pacmворы.

\section{Введение}

В последние годы особое внимание обращено на такие заболевания желудочно-кишечного тракта, как язвенная болезнь желудка и двенадцатиперстной кишки. По данным мировой статистики, язвенная болезнь распространена примерно у 5-10 \% взрослого населения [1]. На текущий момент в России и за рубежом существуют эффективные способы лечения язвенной болезни желудка и двенадцатиперстной кишки, в основе которых лежит применение препарата «Де-Нол», выпускаемого фирмой «Astellas Pharma Europe B.V.» (Нидерланды) [2-6]. Фармакологически активной частью препарата «Де-Нол» является висмута трикалия дицитрат, который представляет собой растворимые в воде комплексные калий-аммонийные соли висмута и лимонной кислоты. Данный активный компонент входит в соответствии с Распоряжением Правительства Российской Федерации от 23 октября 2017 г. № 2832-р в Перечень жизненно необходимых и важнейших лекарственных препаратов для медицинского применения на 2018 г. Исходным соединением при получении висмута трикалия дицитрата является цитрат висмута состава $\mathrm{BiC}_{6} \mathrm{H}_{5} \mathrm{O}_{7}$, который также широко используется в микробиологии для приготовления питательных сред.

В литературе описаны различные составы соединений висмута с лимонной кислотой. Показано [7], что из молочно-уксуснокислого раствора при соотношении 1 моля оксида висмута к 1 молю лимонной кислоты висмут осаждается в виде соединения состава $(\mathrm{BiOH})_{3}\left(\mathrm{C}_{6} \mathrm{H}_{5} \mathrm{O}_{7}\right)_{2}$. 
Цитрат висмута состава $\mathrm{BiC}_{6} \mathrm{H}_{5} \mathrm{O}_{7}$ получен в результате добавления раствора нитрата висмута в раствор цитрата аммония с последующим нагревом смеси на паровой бане $[8,9]$, а также по реакции взаимодействия твердого основного нитрата висмута с раствором лимонной кислоты при температуре процесса $(60 \pm 10){ }^{\circ} \mathrm{C}[10]$. Установлено, что цитрат висмута состава $\mathrm{BiC}_{6} \mathrm{H}_{5} \mathrm{O}_{7} \cdot \mathrm{H}_{2} \mathrm{O}$ образуется в виде осадка при добавлении раствора лимонной кислоты в висмутсодержащий раствор, полученный в результате растворения нитрата висмута в ледяной уксусной кислоте, а также при взаимодействии висмута гидроксида или оксокарбоната с раствором лимонной кислоты при кипячении [9]. В настоящее время для получения соединений висмута в промышленности используют его азотнокислые растворы.

В этой связи актуален вопрос получения цитрата висмута высокой чистоты для отечественного противоязвенного лекарственного средства в результате переработки висмутсодержащих азотнокислых растворов.

\section{Материалы и методы}

В работе использовали минеральные кислоты, соли и щелочи квалификации «хч» или «ос.ч». Исходные растворы нитрата висмута (360 г/л) готовили растворением оксида висмута квалификации «ос.ч. 13-3» в азотной кислоте с концентрацией 6 моль/л. Осадки, полученные в результате добавления к висмутсодержащим растворам лимонной кислоты или раствора трехзамещенного цитрата натрия, отделяли от маточного раствора фильтрацией, промывали дистиллированной водой и сушили на воздухе. Содержание висмута в растворах и осадках определяли фотоколориметрическим методом в присутствии КІ на приборе КФК-2. Продукты осаждения предварительно растворяли в азотной кислоте $(1: 1)$. Определение анионов лимонной и азотной кислот в твердых продуктах реакций проводили после их перевода в раствор предварительной обработкой осадков раствором $2 \mathrm{M} \mathrm{NaOH}$ при $70-90{ }^{\circ} \mathrm{C}$. Концентрацию нитрат-ионов определяли калориметрическим методом с салицилатом натрия $[11,12]$, содержание цитрат-ионов - методом перманганатометрического титрования [13]. Рентгенофазовый анализ (РФА) продуктов реакции проводили на дифрактометре Bruker D8 Advance с использованием $\mathrm{Cu}_{\mathrm{K \alpha}}$-излучения. Скорость вращения счетчика 0,5 град·мин ${ }^{-1}$. Измерение значений $\mathrm{pH}$ растворов осуществляли рН-метре ОР-264/1 (Венгрия) с помощью стеклянного или обновляемого твердого электрода.

Осаждение висмута из азотнокислых растворов проводили добавлением растворов лимонной кислоты или цитрата натрия при молярных отношениях цитрат-ионов к висмуту, равных $0,125-2,5$, и температурах 22 и $60^{\circ} \mathrm{C}$ в течение 2 ч. Взаимодействие в системе оксогидроксонитрат висмута (ОГНВ) - водный раствор лимонной кислоты исследовали при следующих условиях: навеска ОГНВ 10 г, молярное отношение $\left[\mathrm{Cit}^{3-}\right] /\left[\mathrm{Bi}^{3+}\right]=1,15$. Исследовали временной диапазон $0,25-6$ ч, температуры процесса $(22 \pm 2){ }^{\circ} \mathrm{C}$ и $(70 \pm 2){ }^{\circ} \mathrm{C}$. Твердые продукты, полученные в результате обработки ОГНВ раствором лимонной кислоты, отделяли от маточного раствора фильтрацией, промывали дистиллированной водой и сушили на воздухе.

\section{Результаты и обсуждение}

При осаждении из азотнокислых растворов степень осаждения висмута с ростом температуры возрастает (рис. 1, кривые 1 и 3). Последнее обусловлено тем, что комплексообразова- 
ние висмута с нитрат-ионами протекает в основном по экзотермическим реакциям [14]. Вследствие этого с ростом температуры снижается значение функции закомплексованности висмута с нитрат-ионами и, соответственно, повышается его извлечение в осадок в виде цитрата. Из рисунка также видно, что в случае осаждения висмута из азотнокислых растворов при использовании в качестве доноров цитрат-ионов вместо лимонной кислоты цитрата натрия (рис. 1, кривые 1 и 2) степень осаждения висмута повышается, что обусловлено снижением концентрации ионов водорода в растворе. Следует отметить, что в случае использования цитрата натрия при $n \geq 1,1$ цитрат висмута начинает осаждаться как при $22^{\circ} \mathrm{C}$, так и при $60^{\circ} \mathrm{C}$, в виде натриевой формы.

По данным рентгенофазового анализа, при осаждении висмута из азотнокислых растворов в отсутствие цитрат-ионов происходит образование ОГНВ, причем при температуре процесса $22{ }^{\circ} \mathrm{C}$ образуется основной нитрат состава $\left[\mathrm{Bi}_{6} \mathrm{O}_{4}(\mathrm{OH})_{4}\right]\left(\mathrm{NO}_{3}\right)_{6} \cdot 4 \mathrm{H}_{2} \mathrm{O}$, а при $60{ }^{\circ} \mathrm{C}-$ $\left[\mathrm{Bi}_{6} \mathrm{O}_{4}(\mathrm{OH})_{4}\right]\left(\mathrm{NO}_{3}\right)_{6} \cdot \mathrm{H}_{2} \mathrm{O}[15,16]$. При добавлении к азотнокислым висмутсодержащим растворам цитрат-ионов при отношении последних к висмуту меньших или равных 0,7 и температурах 22 и $60{ }^{\circ} \mathrm{C}$ висмут осаждается в виде соединения состава $\mathrm{Bi}_{6}(\mathrm{OH})_{6}\left(\mathrm{C}_{6} \mathrm{H}_{5} \mathrm{O}_{7}\right)_{4} \cdot 6 \mathrm{H}_{2} \mathrm{O}$ (рис. 2 , дифрактограмма 1). Полученные осадки содержат, \%: висмута - 55,70 (вычислено 56,47 \%), цитрат-ионов - 33,57 (вычислено 34,07 \%), углерода - 12,41 (вычислено 12,98 \%), водорода - 1,70 (вычислено $1,73 \%$ ), молярное отношение цитрат-ионов к висмуту в осадке равно $0,67 \pm 0,01$. Соединение с подобным отношением $(n)$ получено ранее при осаждении висмута из молочно-уксуснокислых растворов, и ему приписан состав $(\mathrm{BiOH})_{3}\left(\mathrm{C}_{6} \mathrm{H}_{5} \mathrm{O}_{7}\right)_{2}$ [7], а соединение состава $\left[\mathrm{Bi}_{6}(\mathrm{OH})_{6}\left(\mathrm{C}_{6} \mathrm{H}_{5} \mathrm{O}_{7}\right)_{4}\right]_{\mathrm{n}}$ зарегистрировано в России фирмой «Яманучи Юроп» в качестве лекарственной субстанции, которая используется при приготовлении противоязвенного препарата «Де-Нол» [17]. При проведении процесса осаждения при температуре $22{ }^{\circ} \mathrm{C}$ и $n$, равном $1,0-2,5$, осадок представляет собой моногидрат оксоцитрата висмута состава

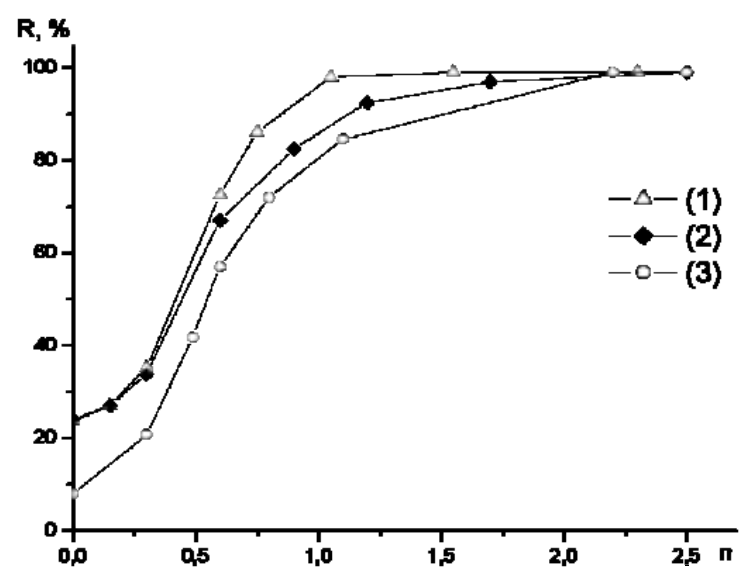

Рис. 1. Зависимость степени осаждения (R) висмута из азотнокислых растворов от молярного отношения цитрат-ионов к висмуту $(n)$ в растворах при использовании в качестве осадителя цитрата натрия $(1,3)$ и лимонной кислоты (2). Температура, ${ }^{\circ} \mathrm{C}: 22(3)$ и $60(1,2)$

Fig. 1. Dependence of the degree of bismuth precipitation (R) from nitric acid solutions on the molar ratio of citrate ions to bismuth $(n)$ in solutions when sodium citrate $(1,3)$ and citric acid $(2)$ are used as a precipitant. Temperature, ${ }^{\circ} \mathrm{C}: 22(3)$ and $60(1,2)$ 


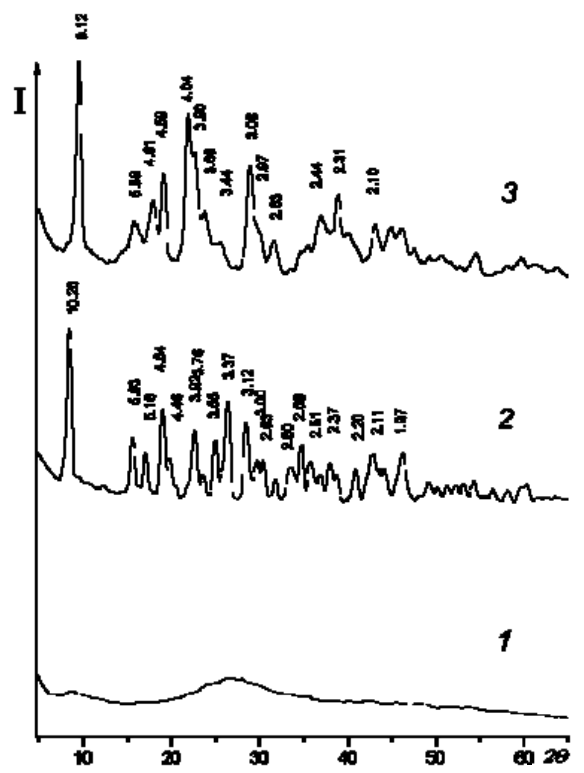

Рис. 2. Дифрактограммы образцов цитратов висмута: $\mathrm{Bi}_{6}(\mathrm{OH})_{6}\left(\mathrm{C}_{6} \mathrm{H}_{5} \mathrm{O}_{7}\right)_{4} \cdot 6 \mathrm{H}_{2} \mathrm{O}(1) ; \mathrm{BiOC}_{6} \mathrm{H}_{7} \mathrm{O}_{7} \cdot \mathrm{H}_{2} \mathrm{O}$ (2); $\mathrm{BiC}_{6} \mathrm{H}_{5} \mathrm{O}_{7}$ (3)

Fig. 2. Diffractograms of bismuth citrate samples: $\mathrm{Bi}_{6}(\mathrm{OH})_{6}\left(\mathrm{C}_{6} \mathrm{H}_{5} \mathrm{O}_{7}\right){ }_{4} \cdot 6 \mathrm{H}_{2} \mathrm{O}(1) ; \mathrm{BiOC}_{6} \mathrm{H}_{7} \mathrm{O}_{7} \cdot \mathrm{H}_{2} \mathrm{O}(2) ; \mathrm{BiC}_{6} \mathrm{H}_{5} \mathrm{O}_{7}$ (3)

$\mathrm{BiC}_{6} \mathrm{H}_{7} \mathrm{O}_{7} \cdot \mathrm{H}_{2} \mathrm{O}$, имеющий дифракционные максимумы со значениями $d / n 10.26,5.63,4.64,3.92$, $3.37,2.11 \AA$ (рис. 2, дифрактограмма 2). Содержание в осадке, \%: висмута - 48,38 (вычислено 48,14\%), цитрат-ионов - 43,82 (вычислено 44,03 \%), углерода - 16,70 (вычислено 16,60 \%), водорода $-1,88$ (вычислено 2,09\%), молярное отношение цитрат-ионов к висмуту в осадке равно $0,98 \pm 0,03$. При температуре $60^{\circ} \mathrm{C}$ в исследованной области $n 1,0-2,3$ висмут осаждается в виде соединения состава $\mathrm{BiC}_{6} \mathrm{H}_{5} \mathrm{O}_{7}$, со значениями дифракционных максимумов $d / n$ 9.12, $4.59,4.04,3.08,2.10 \AA$ (рис. 2, дифрактограмма 3). Содержание в осадке, \%: висмута - 51,62 (вычислено 52,50 \%), цитрат-ионов - 46,24 (вычислено 47,50 \%), углерода - 17,88 (вычислено $18,10 \%$ ), водорода - 1,20 (вычислено $1,27 \%$ ), молярное отношение цитрат-ионов к висмуту в осадке равно $0,99 \pm 0,02$. Следует отметить, что соединение подобного состава может быть получено также при проведении процесса при температуре $22{ }^{\circ} \mathrm{C}$ с последующим нагреванием пульпы до $60{ }^{\circ} \mathrm{C}$.

Таким образом, из азотнокислых растворов в зависимости от отношения цитрат-ионов к висмуту в системе и температуры процесса висмут осаждается в виде трех соединений составов $\mathrm{BiC}_{6} \mathrm{H}_{5} \mathrm{O}_{7}, \mathrm{BiOC}_{6} \mathrm{H}_{7} \mathrm{O}_{7} \cdot \mathrm{H}_{2} \mathrm{O}$ и $\mathrm{Bi}_{6}(\mathrm{OH})_{6}\left(\mathrm{C}_{6} \mathrm{H}_{5} \mathrm{O}_{7}\right)_{4} \cdot 6 \mathrm{H}_{2} \mathrm{O}$. Составы полученных соединений подтверждены данными химического и рентгенофазового анализов.

Данные электронно-микроскопических исследований показали, что полученные цитраты висмута имеют различную морфологию. Так, средний цитрат висмута представляет собой агрегаты размером до 10 мкм, состоящие из мелких кристаллов размером порядка 0,1 мкм, моногидрат оксоцитрата висмута - удлиненные призматические кристаллы длиной до 15 мкм и в поперечном сечении от 0,5 до 3 мкм, а гексагидрат гидроксоцитрата висмута - агрегаты размером до 5 мкм, состоящие из мелких аморфных частиц размером от 0,1 до 0,5 мкм. 
Следует отметить, что при осаждении висмута из технологических азотнокислых растворов совместно с висмутом соосаждаются такие основные сопутствующие металлы, как свинец, серебро и др. При осаждении висмута из азотнокислых растворов разбавлением водой или добавлением щелочных реагентов (гидроксидов или карбонатов натрия и аммония) в зависимости от $\mathrm{pH}$ среды и температуры процесса образуются оксогидроксонитраты следующих составов: $\left[\mathrm{Bi}_{6} \mathrm{O}_{4}(\mathrm{OH})_{4}\right]\left(\mathrm{NO}_{3}\right)_{6} \cdot 4 \mathrm{H}_{2} \mathrm{O}[18],\left[\mathrm{Bi}_{6} \mathrm{O}_{4}(\mathrm{OH})_{4}\right]\left(\mathrm{NO}_{3}\right)_{6} \cdot \mathrm{H}_{2} \mathrm{O}$ [19], [ $\left[\mathrm{Bi}_{6} \mathrm{O}_{4}(\mathrm{OH})_{4}\left(\mathrm{H}_{2} \mathrm{O}\right)\left(\mathrm{NO}_{3}\right)\right]\left(\mathrm{NO}_{3}\right)_{5}$ [20], $\left[\mathrm{Bi}_{6} \mathrm{O}_{5}(\mathrm{OH})_{3}\right]\left(\mathrm{NO}_{3}\right)_{5} \cdot 3 \mathrm{H}_{2} \mathrm{O}[21],\left[\mathrm{Bi}_{6} \mathrm{O}_{4.5}(\mathrm{OH})_{3.5}\right]_{2}\left(\mathrm{NO}_{3}\right)_{11}$ [22], при этом показано, что осаждение висмута в виде соединений $\left[\mathrm{Bi}_{6} \mathrm{O}_{4}(\mathrm{OH})_{4}\right]\left(\mathrm{NO}_{3}\right)_{6} \cdot \mathrm{H}_{2} \mathrm{O},\left[\mathrm{Bi}_{6} \mathrm{O}_{5}(\mathrm{OH})_{3}\right]\left(\mathrm{NO}_{3}\right)_{5} \cdot 3 \mathrm{H}_{2} \mathrm{O},\left[\mathrm{Bi}_{6} \mathrm{O}_{4}(\mathrm{OH})_{4}\right]\left(\mathrm{NO}_{3}\right)_{6} \cdot 4 \mathrm{H}_{2} \mathrm{O}$ позволяет эффективно отделять висмут от сопутствующих металлов, благодаря чему они могут быть рекомендованы к использованию в качестве прекурсоров в синтезе соединения висмута высокой чистоты [23], в том числе для фармацевтической промышленности. Нами исследован процесс получения цитрата висмута по обменной реакции твердый оксогидроксонитрат висмута - раствор лимонной кислоты. В качестве исходного твердого компонента использовали оксогидроксонитраты висмута составов $\left[\mathrm{Bi}_{6} \mathrm{O}_{4}(\mathrm{OH})_{4}\right]\left(\mathrm{NO}_{3}\right)_{6} \cdot 4 \mathrm{H}_{2} \mathrm{O},\left[\mathrm{Bi}_{6} \mathrm{O}_{5}(\mathrm{OH})_{3}\right]\left(\mathrm{NO}_{3}\right)_{5} \cdot 3 \mathrm{H}_{2} \mathrm{O}$, $\left.\left[\mathrm{Bi}_{6} \mathrm{O}_{4}(\mathrm{OH})_{4}\right]\left(\mathrm{NO}_{3}\right)_{6} \cdot \mathrm{H}_{2} \mathrm{O}\right)$, которые осаждаются на начальной стадии переработки висмутсодержащих азотнокислых растворов. Взаимодействие оксогидроксонитратов висмута с раствором лимонной кислоты исследовано при молярном соотношении цитрат-ионов к висмуту, равном 1,15 .
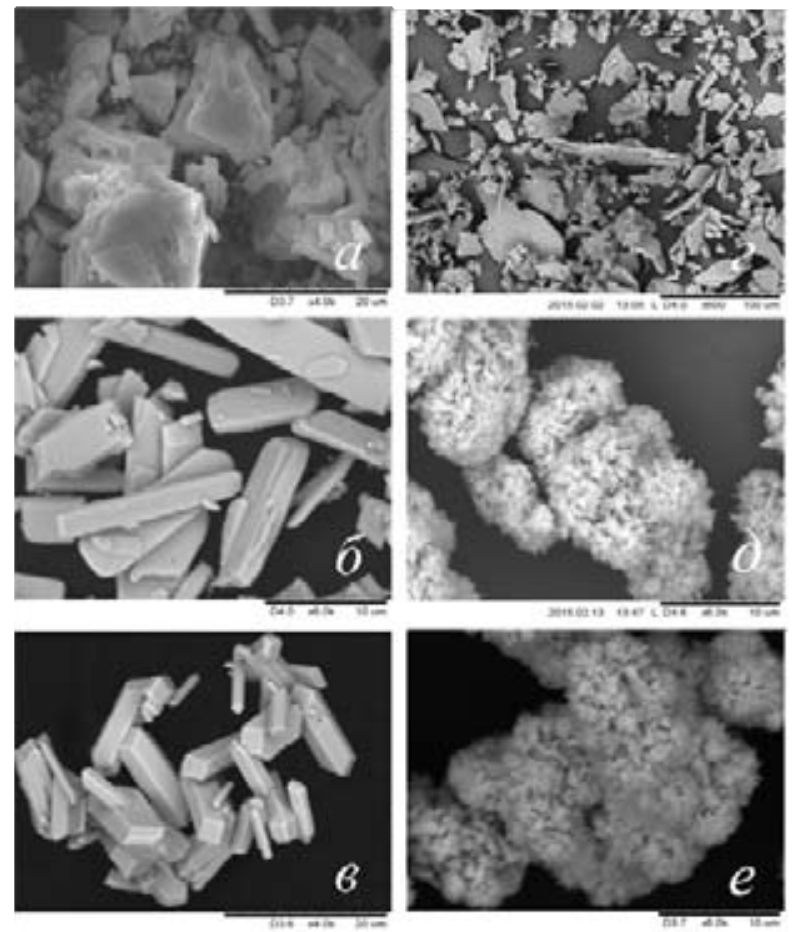

Рис. 3. Электронные микрофотографии образцов ОГНВ $\left.\left[\mathrm{Bi}_{6} \mathrm{O}_{4}(\mathrm{OH})_{4}\right]\left(\mathrm{NO}_{3}\right)_{6} \cdot 4 \mathrm{H}_{2} \mathrm{O}(a), \mathrm{Bi}_{6} \mathrm{O}_{5}(\mathrm{OH})_{3}\right]\left(\mathrm{NO}_{3}\right)_{5} \cdot 3 \mathrm{H}_{2} \mathrm{O}(\sigma)$, $\left[\mathrm{Bi}_{6} \mathrm{O}_{4}(\mathrm{OH})_{4}\right]\left(\mathrm{NO}_{3}\right)_{6} \cdot \mathrm{H}_{2} \mathrm{O}($ ( $)$ и полученных из них цитратов висмута $(2-e)$ соответственно

Fig. 3. Electron micrographs of samples of OXNB the compositions $\left[\mathrm{Bi}_{6} \mathrm{O}_{4}(\mathrm{OH})_{4}\right]\left(\mathrm{NO}_{3}\right)_{6} \cdot 4 \mathrm{H}_{2} \mathrm{O}$ (a), $\left.\mathrm{Bi}_{6} \mathrm{O}_{5}(\mathrm{OH})_{3}\right]\left(\mathrm{NO}_{3}\right)_{5} \cdot 3 \mathrm{H}_{2} \mathrm{O}(b),\left[\mathrm{Bi}_{6} \mathrm{O}_{4}(\mathrm{OH})_{4}\right]\left(\mathrm{NO}_{3}\right)_{6} \cdot \mathrm{H}_{2} \mathrm{O}(c)$ and obtained from them bismuth citrates $(d-f)$, respectively

$$
-482-
$$


Данные электронно-микроскопических исследований показали (рис. 3), что ОГНВ составов $\left[\mathrm{Bi}_{6} \mathrm{O}_{4}(\mathrm{OH})_{4}\right]\left(\mathrm{NO}_{3}\right)_{6} \cdot 4 \mathrm{H}_{2} \mathrm{O},\left[\mathrm{Bi}_{6} \mathrm{O}_{5}(\mathrm{OH})_{3}\right]\left(\mathrm{NO}_{3}\right)_{5} \cdot 3 \mathrm{H}_{2} \mathrm{O},\left[\mathrm{Bi}_{6} \mathrm{O}_{4}(\mathrm{OH})_{4}\right]\left(\mathrm{NO}_{3}\right)_{6} \cdot \mathrm{H}_{2} \mathrm{O}$ имеют разную морфологию. Для ОГНВ состава $\left[\mathrm{Bi}_{6} \mathrm{O}_{4}(\mathrm{OH})_{4}\right]\left(\mathrm{NO}_{3}\right)_{6} \cdot 4 \mathrm{H}_{2} \mathrm{O}$ (рис. $3 a$ ) характерно слоистое строение, что способствует захвату большего количества маточного раствора, содержащего примесные металлы и, как следствие, снижает чистоту продукта. ОГНВ состава $\left[\mathrm{Bi}_{6} \mathrm{O}_{5}(\mathrm{OH})_{3}\right]\left(\mathrm{NO}_{3}\right)_{5} \cdot 3 \mathrm{H}_{2} \mathrm{O}$ (рис. 3б) представляет собой удлинённые плоскопризматические кристаллы длиной 10-40 мкм, шириной 2-5 мкм и толщиной 0,5-1 мкм, ОГНВ состава $\left[\mathrm{Bi}_{6} \mathrm{O}_{4}(\mathrm{OH})_{4}\right]\left(\mathrm{NO}_{3}\right)_{6} \cdot \mathrm{H}_{2} \mathrm{O}$ (рис. 36) - это легкофильтруемый кристаллический осадок, благодаря чему его можно эффективно отделять от раствора, содержащего примесные металлы. Осадок - это сростки короткопризматических кристаллов с максимальным размером единичного кристалла в базисной плоскости 2-10 мкм, а по толщине 1-3 мкм. Цитрат висмута, получаемый из ОГНВ, представляет собой сростки чешуйчатых кристаллов с размерами единичного кристалла 1-3 мкм (рис. 32-e). В опытах по получению цитрата висмута с использованием обменной реакции твердый ОГНВ - раствор лимонной кислоты при массовом соотношении жидкого к твердому (Ж/T), равном 10,4, установлено, что без дополнительного введения азотной кислоты в систему процесс обмена идет медленно, и даже при повышении температуры процесса до $70^{\circ} \mathrm{C}$ количественного выхода цитрата висмута даже через 4 ч после начала реакции достичь не удается. При добавлении различных количеств кислоты в систему при температуре $22{ }^{\circ} \mathrm{C}$ процесс обмена быстрее всего реализуется при равновесном значении $\mathrm{pH}$ 0,5-0,6, что соответствует добавлению $0,5 \mathrm{M}$ азотной кислоты. Цитрат висмута состава $\mathrm{BiC}_{6} \mathrm{H}_{5} \mathrm{O}_{7}$ образуется через 1 ч после начала реакции. Повышение температуры процесса в этих условиях приводит к резкому увеличению скорости обмена и при температурах 50 и $70{ }^{\circ} \mathrm{C}$, по данным РФА, конечный продукт образуется уже через 15 мин после начала реакции, при этом остаточное содержание висмута в растворе составляет примерно 5 г/л.

Исследование взаимодействия ОГНВ с раствором лимонной кислоты при молярном отношении цитрат-ионов к висмуту, равном 1,15 , при добавлении в систему $0,25 \mathrm{M}$ азотной кислоты и температуре $(22 \pm 2){ }^{\circ} \mathrm{C}$ показало, что, согласно данным РФА, через 30 мин после начала процесса осадки представляют собой двухфазные смеси исходных ОГНВ и цитрата висмута состава $\mathrm{BiC}_{6} \mathrm{H}_{5} \mathrm{O}_{7}$ в различных соотношениях, а конечные продукты обмена - цитрат висмута состава $\mathrm{BiC}_{6} \mathrm{H}_{5} \mathrm{O}_{7}$. Молярное отношение цитрат-ионов к висмуту в монофазных образцах равно 1,0 , что соответствует цитрату висмута состава $\mathrm{BiC}_{6} \mathrm{H}_{5} \mathrm{O}_{7}$. Содержание нитрат-ионов в твердых продуктах, полученных в результате взаимодействия в течение 1 ч, при использовании в качестве прекурсора $\left[\mathrm{Bi}_{6} \mathrm{O}_{5}(\mathrm{OH})_{3}\right]\left(\mathrm{NO}_{3}\right)_{5} \cdot 3 \mathrm{H}_{2} \mathrm{O}$ составляет $0,42 \%$, в случае $\left[\mathrm{Bi}_{6} \mathrm{O}_{4}(\mathrm{OH})_{4}\right]\left(\mathrm{NO}_{3}\right)_{6} \cdot 4 \mathrm{H}_{2} \mathrm{O}-$ $0,96 \%$, a c $\left[\mathrm{Bi}_{6} \mathrm{O}_{4}(\mathrm{OH})_{4}\right]\left(\mathrm{NO}_{3}\right)_{6} \cdot \mathrm{H}_{2} \mathrm{O}-1,82 \%$.

Осадки, полученные при продолжительности процесса 2 ч и больше, во всех случаях монофазны и представляют собой цитрат висмута состава $\mathrm{BiC}_{6} \mathrm{H}_{5} \mathrm{O}_{7}$. Содержание нитрат-ионов в цитрате висмута, полученном из ОГНВ составов $\left[\mathrm{Bi}_{6} \mathrm{O}_{5}(\mathrm{OH})_{3}\right]\left(\mathrm{NO}_{3}\right)_{5} \cdot 3 \mathrm{H}_{2} \mathrm{O},\left[\mathrm{Bi}_{6} \mathrm{O}_{4}(\mathrm{OH})_{4}\right]\left(\mathrm{NO}_{3}\right)_{6} \cdot 4 \mathrm{H}_{2} \mathrm{O}$ и $\left[\mathrm{Bi}_{6} \mathrm{O}_{4}(\mathrm{OH})_{4}\right]\left(\mathrm{NO}_{3}\right)_{6} \cdot \mathrm{H}_{2} \mathrm{O}$ после водной промывки, не превышает значений $0,20,0,30$ и $1,00 \%$ соответственно.

Результаты анализа твердых продуктов взаимодействия ОГНВ с раствором лимонной кислоты показали (рис. 4), что содержание нитрат-ионов в осадке постепенно снижается, а цитрат-ионов - увеличивается. Наименьшее содержание нитрат-ионов и наибольшее цитрат-

$$
-483-
$$




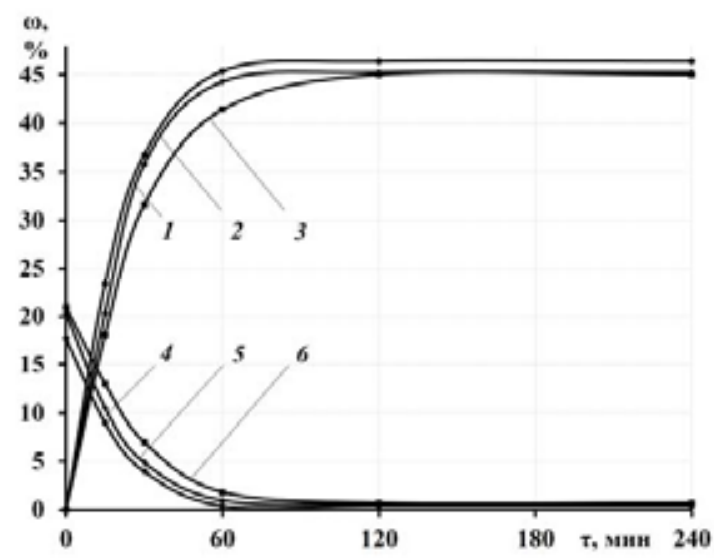

Рис. 4. Зависимость содержания ( $\omega, \%)$ в осадке цитрат- (1-3) и нитрат-ионов (4-6) от времени ( $\tau$, мин) проведения процесса при Ж/Т $=10,4$. Составы ОГНВ: $\left.1,4-\mathrm{Bi}_{6} \mathrm{O}_{5}(\mathrm{OH})_{3}\right]\left(\mathrm{NO}_{3}\right)_{5} \cdot 3 \mathrm{H}_{2} \mathrm{O}_{\text {; }}$ 2, $5-\left[\mathrm{Bi}_{6} \mathrm{O}_{4}(\mathrm{OH})_{4}\right]\left(\mathrm{NO}_{3}\right)_{6} \cdot 4 \mathrm{H}_{2} \mathrm{O} ; 3,6-\left[\mathrm{Bi}_{6} \mathrm{O}_{4}(\mathrm{OH})_{4}\right]\left(\mathrm{NO}_{3}\right)_{6} \cdot \mathrm{H}_{2} \mathrm{O}$

Fig. 4. Dependence of the content $(\omega, \%)$ the citrate- $(1-3)$ and nitrate-ions (4- 6$)$ in sediment on the time ( $\tau$, min) of the process at $L / S=10,4$. Compositions of the OXNB: $\left.1,4-\mathrm{Bi}_{6} \mathrm{O}_{5}(\mathrm{OH})_{3}\right]\left(\mathrm{NO}_{3}\right)_{5} \cdot 3 \mathrm{H}_{2} \mathrm{O} ; 2,5-\left[\mathrm{Bi}_{6} \mathrm{O}_{4}(\mathrm{OH})_{4}\right]\left(\mathrm{NO}_{3}\right)_{6} \cdot 4 \mathrm{H}_{2} \mathrm{O}$; $3,6-\left[\mathrm{Bi}_{6} \mathrm{O}_{4}(\mathrm{OH})_{4}\right]\left(\mathrm{NO}_{3}\right)_{6} \cdot \mathrm{H}_{2} \mathrm{O}$

ионов наблюдается в случае использования ОГНВ состава $\left[\mathrm{Bi}_{6} \mathrm{O}_{4}(\mathrm{OH})_{3}\right]\left(\mathrm{NO}_{3}\right)_{5} \cdot 3 \mathrm{H}_{2} \mathrm{O}$. Повидимому, это обусловлено лучшей его растворимостью в воде по сравнению с ОГНВ двух других составов. При времени взаимодействия 1 ч и массовом соотношении Ж/Т, равном 10,4, получены осадки с содержанием нитрат-ионов $0,42 \%$, а после промывки их водой $-0,2 \%$. Электронно-микроскопические исследования показали (рис. 32-e), что морфология продукта взаимодействия ОГНВ с раствором лимонной кислоты зависит от морфологии исходных веществ. Цитрат висмута, полученный из ОГНВ составов $\left[\mathrm{Bi}_{6} \mathrm{O}_{4}(\mathrm{OH})_{3}\right]\left(\mathrm{NO}_{3}\right)_{5} \cdot 3 \mathrm{H}_{2} \mathrm{O}$ (рис. $3 \partial$ ) и $\left[\mathrm{Bi}_{6} \mathrm{O}_{4}(\mathrm{OH})_{4}\right]\left(\mathrm{NO}_{3}\right)_{6} \cdot \mathrm{H}_{2} \mathrm{O}$ (рис. 3e), представляет собой агрегаты размерами 10-15 мкм, состоящие из чешуйчатых частиц с размерами порядка 1-3 мкм. В то же время продукт, полученный из ОГНВ состава $\left[\mathrm{Bi}_{6} \mathrm{O}_{4}(\mathrm{OH})_{4}\right]\left(\mathrm{NO}_{3}\right)_{6} \cdot 4 \mathrm{H}_{2} \mathrm{O}$, сохраняет морфологию исходного ОГНВ - его слоистое строение (рис. 32). Данный фактор значительно затрудняет получение целевого продукта при использовании в качестве прекурсора соединение состава $\left[\mathrm{Bi}_{6} \mathrm{O}_{4}(\mathrm{OH})_{4}\right]\left(\mathrm{NO}_{3}\right)_{6} \cdot 4 \mathrm{H}_{2} \mathrm{O}$, так как время фильтрации увеличивается в несколько раз.

Таким образом, может быть рекомендован способ получения цитрата висмута путем взаимодействия ОГНВ состава $\left[\mathrm{Bi}_{6} \mathrm{O}_{4}(\mathrm{OH})_{3}\right]\left(\mathrm{NO}_{3}\right)_{5} \cdot 3 \mathrm{H}_{2} \mathrm{O}$ с раствором лимонной кислоты при молярном отношения цитрат-ионов к висмуту, равном 1,15 , добавления в систему $0,25 \mathrm{M}$ азотной кислоты, при температуре процесса $(22 \pm 2)^{\circ} \mathrm{C}$ и массовом отношении Ж/Т, равном 10,4.

При взаимодействии ОГНВ данных составов с раствором лимонной кислоты при температуре $(22 \pm 2)^{\circ} \mathrm{C}$ без дополнительного введения азотной кислоты в систему выход цитрата висмута не превышает 50 \% даже через 6 ч после начала процесса. Для интенсификации процесса получения цитрата висмута из ОГНВ путем их обработки водным раствором лимонной кислоты определены оптимальные условия синтеза: температура и массовое отношение Ж/T.

Установлено, что в случае взаимодействия ОГНВ состава $\left[\mathrm{Bi}_{6} \mathrm{O}_{4}(\mathrm{OH})_{3}\right]\left(\mathrm{NO}_{3}\right)_{5} \cdot 3 \mathrm{H}_{2} \mathrm{O}$ с раствором лимонной кислоты при температуре $(22 \pm 2)^{\circ} \mathrm{C}$ и отношении Ж/Т $=2,3$ (рис. 5 , кривые 


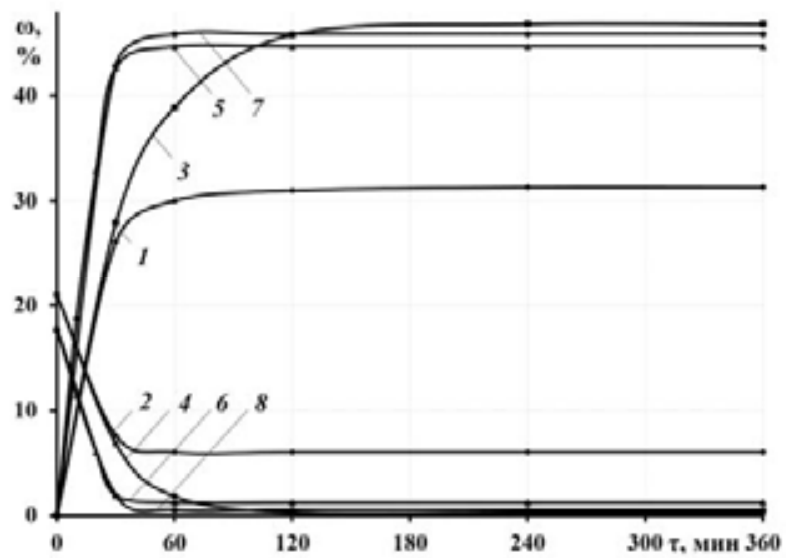

Рис.5. Зависимость содержания в осадке $(\omega, \%)$ цитрат- $(1,3,5,7)$ и нитрат-ионов $(2,4,6,8)$ от времени ( $\tau$, мин) проведения процесса при Ж/T, равном 2,3. Составы ОГНВ: $\left[\mathrm{Bi}_{6} \mathrm{O}_{5}(\mathrm{OH})_{3}\right]\left(\mathrm{NO}_{3}\right)_{5} \cdot 3 \mathrm{H}_{2} \mathrm{O}(1-4)$, $\left[\mathrm{Bi}_{6} \mathrm{O}_{4}(\mathrm{OH})_{4}\right]\left(\mathrm{NO}_{3}\right)_{6} \cdot \mathrm{H}_{2} \mathrm{O}(5-8)$. Температура, ${ }^{\circ} \mathrm{C}:(22 \pm 2)(1,2,5,6),(70 \pm 2)(3,4,7,8)$

Fig.5. Dependence of the content in the sediment $(\omega, \%)$ of citrate $(1,3,5,7)$ and nitrate ions $(2,4,6,8)$ on the time $(\tau, \mathrm{min}))$ of the process at $L / S=2,3$. Compositions of the OXNB: $\left[\mathrm{Bi}_{6} \mathrm{O}_{5}(\mathrm{OH})_{3}\right]\left(\mathrm{NO}_{3}\right)_{5} \cdot 3 \mathrm{H}_{2} \mathrm{O}(1-4)$, $\left[\mathrm{Bi}_{6} \mathrm{O}_{4}(\mathrm{OH})_{4}\right]\left(\mathrm{NO}_{3}\right)_{6} \cdot \mathrm{H}_{2} \mathrm{O}(5-8)$. Temperature, ${ }^{\circ} \mathrm{C}:(22 \pm 2)(1,2,5,6),(70 \pm 2)(3,4,7,8)$

$1,2)$ процесс обмена продолжительный, и даже через 6 ч осадок содержит 6 \% нитрат-ионов. При повышении температуры процесса до $(70 \pm 2)^{\circ} \mathrm{C}$ и отношении Ж $/ \mathrm{T}=2,3$ цитрат висмута без примеси образуется через 2 ч после начала проведения процесса.

При взаимодействии ОГНВ состава $\left[\mathrm{Bi}_{6} \mathrm{O}_{4}(\mathrm{OH})_{4}\right]\left(\mathrm{NO}_{3}\right)_{6} \cdot \mathrm{H}_{2} \mathrm{O}$ с раствором лимонной кислоты при температуре $(22 \pm 2){ }^{\circ} \mathrm{C}$ и отношении Ж/Т, равном 2,3 , процесс обмена нитрат-ионов на цитрат завершается уже через 0,5 ч после начала реакции. Кривые при этом выходят на плато (рис. 5, кривые 5,6), содержание $\mathrm{NO}_{3}{ }^{-}$в твердой фазе не превышает $1,5 \%$, а содержание $\mathrm{C}_{6} \mathrm{H}_{5} \mathrm{O}_{7}{ }^{3-}$ достигает почти 45 \%. Из данных РФА и химического анализа следует, что конечный продукт реакции обмена представляет собой средний цитрат висмута состава $\mathrm{BiC}_{6} \mathrm{H}_{5} \mathrm{O}_{7}$. Остаточная концентрация висмута в растворе после завершения процесса равна 0,5-1,0 г/л. С повышением температуры процесса до $(70 \pm 2){ }^{\circ} \mathrm{C}$ в этих же условиях образование цитрата висмута наблюдается через 0,5 ч.

Таким образом, для получения цитрата висмута из ОГНВ путём взаимодействия его с раствором лимонной кислоты при отношении Ж/Т, равном 2,3, и температуре процесса $(22 \pm 2){ }^{\circ} \mathrm{C}$ целесообразно использовать в качестве прекурсора ОГНВ состава $\left[\mathrm{Bi}_{6} \mathrm{O}_{4}(\mathrm{OH})_{4}\right]\left(\mathrm{NO}_{3}\right)_{6} \cdot \mathrm{H}_{2} \mathrm{O}$.

\section{Выводы}

1. Показано, что висмут осаждается из азотнокислых растворов в зависимости от концентрации добавляемой в систему лимонной кислоты и температуры процесса в виде трех соединений различного состава. При осаждении из азотнокислых растворов добавлением к ним растворов лимонной кислоты или цитрата натрия при температурах $(22 \pm 2)$ и $(60 \pm 5){ }^{\circ} \mathrm{C}$ и отношении цитрат-ионов к висмуту, меньших или равных 0,7 , висмут осаждается в виде рентгеноаморфного продукта состава $\mathrm{Bi}_{6}(\mathrm{OH})_{6}\left(\mathrm{C}_{6} \mathrm{H}_{5} \mathrm{O}_{7}\right)_{4} \cdot 6 \mathrm{H}_{2} \mathrm{O}$. При температуре процесса $(22 \pm 2){ }^{\circ} \mathrm{C}$ и молярном отношении цитрат-ионов к висмуту в растворе не менее 1.0 он осаждается в виде 
соединения состава $\mathrm{BiOC}_{6} \mathrm{H}_{7} \mathrm{O}_{7} \cdot \mathrm{H}_{2} \mathrm{O}$, а при температуре $(60 \pm 5)^{\circ} \mathrm{C}$ осаждаемое соединение имеет состав $\mathrm{BiC}_{6} \mathrm{H}_{5} \mathrm{O}_{7}$.

2. Установлено, что цитрат висмута состава $\mathrm{BiC}_{6} \mathrm{H}_{5} \mathrm{O}_{7}$ высокой чистоты из висмутсодержащих азотнокислых растворов целесообразно получать следующим образом: проводить очистку висмута от сопутствующих металлов осаждением его в виде тригидрата оксогидроксонитрата состава $\left[\mathrm{Bi}_{6} \mathrm{O}_{4}(\mathrm{OH})_{3}\right]\left(\mathrm{NO}_{3}\right)_{5} \cdot 3 \mathrm{H}_{2} \mathrm{O}$; переводить его в цитрат висмута обработкой водным раствором лимонной кислоты при массовом отношении Ж/Т $=10,4$ при $\mathrm{pH} 0,1-0,3$ и температуре процесса $(22 \pm 2){ }^{\circ} \mathrm{C}$ либо водным раствором лимонной кислоты при Ж/Т $=2,3$ и температуре процесса $(70 \pm 2)^{\circ} \mathrm{C}$.

3. Показано, что цитрат висмута высокой чистоты может быть получен также в результате обработки моногидрата оксогидроксонитрата висмута состава $\left[\mathrm{Bi}_{6} \mathrm{O}_{4}(\mathrm{OH})_{4}\right]\left(\mathrm{NO}_{3}\right)_{6} \cdot \mathrm{H}_{2} \mathrm{O}$ водным раствором лимонной кислоты при Ж/Т = 2,3 при температуре процесса $(22 \pm 2){ }^{\circ} \mathrm{C}$.

\section{Список литературы}

1. Meurer L.N., Bower D.J. Management of Helicobacter pylori infection. American Family Physician 2002. Vol. 65 (7). P. 1327-1336.

2. Павлов А.И., Кириллов С.М., Пономаренко Д.С., Хаваншанов А.К., Фадина Ж.В., Бобкова И.В., Саввин В.Ю. Сравнительное исследование эффективности и безопасности использования препаратов коллоидного висмута трикалия дицитрата у больных с язвенной болезнью желудка и двенадцатиперстной кишки. Российский медицинский журнал 2016. Т. 24 (26), C. 1782-1787. [Pavlov A.I., Kirillov S.M., Ponomarenko D.S., Khavanshanov A.K., Fadina Zh.V., Bobkova I.V., Savvin V.Yu. A comparative study of the efficacy and safety of using colloidal bismuth preparations of tricalium dicitrate in patients with peptic ulcer of the stomach and duodenum. Russian Medical Journal 2016. Vol. 24 (26), P. 1782-1787. (In Russ.)]

3. Бунова С.С., Мозговой С.И., Рыбкина Л.Б., Усачева Е.В., Назаров А.Н. Качество жизни у пациентов с хроническим Helicobacter pylori - ассоциированным гастритом при использовании эрадикационной терапии первой линии совместно с висмутом трикалия дицитратом. Сибирский медицинский журнал 2013. T. 118 (3), C. 26-29. [Bunova S.S., Mozgovoy S.I., Rybkina L.B., Usacheva E.V., Nazarov A.N. Quality of life in patients with chronic Helicobacter pylori-associated gastritis when using first-line eradication therapy together with bismuth-tricalium dicitrate. Siberian Medical Journal 2013. Vol. 118 (3), P. 26-29. (In Russ.)]

4. Маслова Е.П., Бязрова В.В., Полищук В.Т., Ильяшенко Ю.Н. Оценка эффективности лечения заболеваний, обусловленных хеликобактерной инфекцией. Проблемы экологической $и$ медицинской генетики и клинической иммунологии 2010. № 3 (99), C. 403-409. [Maslova E.P., Bazarova V.V., Polischuk V.T., Ilyashenko Yu.N. Evaluation of the effectiveness of treatment of diseases caused by Helicobacter pylori infection. Problems of ecological and medical genetics and clinical immunology 2010. Vol. 3 (99), P. 403-409. (In Russ.)]

5. Афанасьева Т.С., Перевозщикова Е.Э., Вахрушев Я. М. Клиническая эффективность ДеНола у больных язвенной болезнью. Экспериментальная и клиническая гастроэнтерология 2008. № 4, C. 31-34. [Afanasyeva T.S., Perevozchikova E.E., Vakhrushev Ya. M. Clinical efficacy of De-Nol in patients with peptic ulcer. Experimental and clinical gastroenterology 2008. Vol. 4, P. 31-34. (In Russ.)]] 
6. Dore M. P., Graham D. Y., Mele R., Marras L., Nieddu S., Manca A., Realdi G. Colloidal Bismuth Subcitrate - Based Twice-a-Day Quadruple Therapy as Primary or Salvage Therapy for Helicobacter pylori Infection. The American journal of gastroenterology 2002. Vol. 97 (4), P. 857-860.

7. Кирхгоф Г.А., Спектор М.О. Лимоннокислый висмут. Химико-фармачевтическая промьлиленность 1933. № 3. С. 122-123. [Kirchhoff G.A., Spector M.O. Bismuth citrate. Chemical and pharmaceutical industry 1933. Vol. 3. P. 122-123. (In Russ.)]

8. Швицер Ю. Производство химико-фармацевтических и технохимических препаратов. М.: Л.: ОНТИ, 1934. 490 с. [Shvitser J. Manufacture of chemical-pharmaceutical and technochemical preparations. Moscow: L .: ONTI, 1934. 490 p. (In Russ.)]

9. Туркевич Н.M. Растворимые соединения висмута. І. Цитрат висмута, его аквосоединения и аммиакат. Украинский химический журнал 1949. Т. 15 (2), С. 243-247. [Turkevich N.M. Soluble bismuth compounds. I. Bismuth citrate, its aquatic compounds and ammonia. Ukrainian chemical journal 1949. Vol. 15 (2), P. 243-247. (In Russ.)]

10. Афонина Л.И., Найденко Е.С., Юхин Ю.М., Данилова Л.Е. Синтез высокочистого цитрата висмута с использованием реакции твердое - раствор. Химия в интересах устойчивого развития 2009. T. 17 (3), C. 243-249. [Afonina L.I., Naidenko E.S., Yukhin Yu.M., Danilova L.E. Synthesis of high-purity bismuth citrate using a solid-solution reaction. Chemistry for Sustainable Development 2009. T. 17 (3), Р. 243-249. (In Russ.)]

11. Методы анализа питьевой воды. Госты, сборник. ГОСТ 18826-73 (на $\left.\mathrm{NO}_{3}^{-}\right)$.

12. Лурье Ю.Ю. Аналитическая химия промышленных сточных вод. М.: Химия, 1994. 448 c. [Lurye Yu.Yu. Analytical chemistry of industrial wastewater. Moscow: Chemistry, 1994. 448 p. (In Russ.)]

13. Эшворт М.Р.Ф. Титриметрические методы анализа органических соединений. Часть II. Методы косвенного титрования. М.: Химия, 1972. 1108 c. [Eshworth M.R.F. Titrimetric methods for the analysis of organic compounds. Part II. Methods of indirect titration. M .: Chemistry, 1972. 1108 p. (In Russ.)]

14. Федоров В.А., Калош Т.Н., Миронов В.Е. Исследование нитратных комплексов трехвалентного висмута. Журнал неорганической химии 1971. Т. 16 (4), С. 1014-1019. [Fedorov V.A., Kalosh T.N., Mironov V.E. Investigation of nitrate complexes of trivalent bismuth. Journal of Inorganic Chemistry 1971. Vol. 16 (4), P. 1014-1019. (In Russ.)]

15. Lazarini F. Tetra- $\mu_{3}$-hydroxo-tetra- $\mu_{3}$-oxo-hexabismuth(III)nitrate tetrahydrate $\left[\mathrm{Bi}_{6} \mathrm{O}_{4}(\mathrm{OH})_{4}\right]$ $\left(\mathrm{NO}_{3}\right)_{6} \cdot 4 \mathrm{H}_{2} \mathrm{O}$. Crystal structure communications 1979. V. 8, P. 69-74. [Lazarini F. Tetra- $\mu 3$-hydroxotetra- $\mu$ 3-oxo-hexabismuth (III) nitrate tetrahydrate $\left[\mathrm{Bi}_{6} \mathrm{O}_{4}(\mathrm{OH})_{4}\right]\left(\mathrm{NO}_{3}\right)_{6} \cdot 4 \mathrm{H}_{2} \mathrm{O}$. Crystal structure communications 1979. V. 8, P. 69-74.]

16. Афонина Л.И., Юхин Ю.М., Ворсина И.А. О продуктах гидролиза азотнокислых растворов висмута. Сибирский химический журнал 1993. № 3, С. 13-19. [Afonina L.I., Yukhin Yu.M., Vorsina I.A. On the products of hydrolysis of nitric acid solutions of bismuth. Siberian Chemical Journal 1993. Vol. 3, P. 13-19. (In Russ.)]

17. Де-Нол. Коллоидный субцитрат висмута. Излечение от гастрита и язвенной болезни. - Издание Московского представительства фармацевтической фирмы Яманучи Юроп (Yamanuchi Europe) Нидерланды. - Москва, 1977. Зарегистрирован в РФ, регистрационный номер П № 012626/01-2001 от 26.01.2001. [De-Nol. Colloidal subcitrate of bismuth. Cure for gastritis 
and peptic ulcer. - Publishing of the Moscow representative office of the pharmaceutical company Yamanuchi Europe Netherlands. - Moscow, 1977. Registered in the Russian Federation, registration number P No. 012626 / 01-2001 of 26.01.2001. (In Russ.)]]

18. Lazarini F. Tetra- $\mu 3$-hydroxo-tetra- $\mu 3$-oxo-hexabismuth(III)nitrate tetrahydrate $\left[\mathrm{Bi}_{6} \mathrm{O}_{4}(\mathrm{OH})_{4}\right]\left(\mathrm{NO}_{3}\right)_{6} \cdot 4 \mathrm{H}_{2} \mathrm{O}$. Crystal structure communications 1979. V. 8. P. $69-74$.

19. Sundvall B. Crystal and molecular structure of tetraoxotetrahydroxobismuth (III) nitrate monohydrate, $\mathrm{Bi}_{6} \mathrm{O}_{4}(\mathrm{HO})_{4}\left(\mathrm{NO}_{3}\right)_{6} \cdot \mathrm{H}_{2} \mathrm{O}$. Acta Chemica Scandinavica 1979. V. A33, №3. P.219-224.

20. Lazarini F. Bismuth basic nitrate $\left[\mathrm{Bi}_{6}\left(\mathrm{H}_{2} \mathrm{O}\right)\left(\mathrm{NO}_{3}\right) \mathrm{O}_{4}(\mathrm{OH})_{4}\right]\left(\mathrm{NO}_{3) 5}\right.$. Acta Crystallographica 1979. B. 35. P. 448-450.

21. Lazarini $F$. The crystal structure of bismuth basic nitrate, $\left[\mathrm{Bi}_{6} \mathrm{O}_{5}(\mathrm{OH})_{3}\right]\left(\mathrm{NO}_{3}\right)_{5} \cdot 3 \mathrm{H}_{2} \mathrm{O}$. Acta Crystallographica 1978. Vol. 34, № 11. P. 3169-3173.

22. Henry N., Evain M., Deniard P., Jobic S., Mentré O., Abraham F. $\left[\mathrm{Bi}_{6} \mathrm{O}_{4.5}(\mathrm{OH})_{3.5}\right]_{2}\left(\mathrm{NO}_{3}\right)_{11}$ : A new anhydrous bismuth basic nitrate. Synthesis and structure determination from twinned crystals. Journal of Solid State Chemistry 2003. V. 176. P. 127-136.

23. Юхин Ю.М., Михайлов Ю.И. Химия висмутовых соединений и материалов. Новосибирск: Издательство СО РАН, 2001. 360 c. [Yukhin Yu.M., Mikhailov Yu.I. Chemistry of bismuth compounds and materials. Novosibirsk: Publishing House of the SB RAS, 2001. 360 p. (In Russ.)] 